\title{
Variation of Hyporheic Temperature Profiles in a Low Gradient Third-Order Agricultural Stream-A Statistical Approach
}

\author{
Vanessa Beach, Eric W. Peterson \\ Department of Geography-Geology, Illinois State University, Normal, USA. \\ Email: ewpeter@ilstu.edu \\ Received February $7^{\text {th }}, 2013$; revised March $10^{\text {th }}, 2013$; accepted March $19^{\text {th }}, 2013$
}

Copyright (C) 2013 Vanessa Beach, Eric W. Peterson. This is an open access article distributed under the Creative Commons Attribution License, which permits unrestricted use, distribution, and reproduction in any medium, provided the original work is properly cited.

\begin{abstract}
Sediment size governs advection, controlling the hydraulic conductivity of the stratum, and conduction, influencing the amount of surface area in contact between the sediment particles. To understand the role of sediment particle size on thermal profiles within the hyporheic zone, a statistical approach, involving general summary statistics and time series cross-correlation, was employed. Data were collected along two riffles: Site 1: gravel $\left(\mathrm{d}_{50}=3.9 \mathrm{~mm}\right)$ and Site 2: sand $\left(\mathrm{d}_{50}=0.94 \mathrm{~mm}\right)$.Temperature probe grids collected 15-minute temperature data at $30,60,90$, and $140 \mathrm{~cm}$ below the streambed surface over a 6-month period. Surface water and air temperature were recorded. Diel temperature signal penetration depth was limited to the upper $30 \mathrm{~cm}$ of the streambed and was driven by advection. Surface seasonal trends were detected at greater depths, indicating that thermal pulses are transmitted initially by advection and by conduction to areas deeper in the hyporheic zone. Site 1 showed a high degree of thermal heterogeneity via a localized downwelling zone within a gaining stream environment. Site 2 exhibited a vertically and horizontally homogenized thermal environment attributed to an increased amount of sand sediments that limited advection and significant groundwater discharge that mediated the effects of downwelling surface water.
\end{abstract}

Keywords: Hyporheic Zone; Temperature; Time Series Analysis; Cross-Correlation

\section{Introduction}

Temperature is a basic parameter that controls physical, ecological, and biogeochemical activities in aquatic systems [1-3]. Water temperature studies have had significant impacts on our knowledge of hydrogeology. Evaluation of streambed temperature profiles has been used to quantify groundwater/stream interactions [4], delineate flow paths in the hyporheic zone (HZ) [5], and assist in the evaluation of factors that generate change within thermal profiles [6]. The thermal regime of the HZ controls organic matter decomposition, fish egg incubation, and invertebrate diapauses $[7,8]$.

The HZ is the area below the stream channel where surface and groundwater mix [5,9]. HZ temperatures are controlled by the mixing of groundwater and surface water, reflecting the rates of infiltrating surface water and upwelling groundwater [10], disregarding geothermal influences, and surface water temperatures show both diel and seasonal fluctuations [11-13]. Differences between surface water temperature and subsurface temperature are a function of diel temperature cycles [14]. Dogwiler and Wicks [15] show that with increasing depth and/or distance from infiltration sites, the diel and seasonal fluctuations of surface water become attenuated and lagged. These patterns can be a valuable tool in defining $\mathrm{HZ}$ depth and extent [13,16-18]. However, delineations of $\mathrm{HZ}$ extent are not constant through time, as shown by Fraser and Williams [19], whose results suggest that the extent of the HZ varies seasonally as well as with eventbased fluctuations [20].

While HZ temperatures are dominantly controlled by advection, conduction can also play a significant role [21, 22]. The influence of both advection and conduction on hyporheic water temperatures suggests that sediment particle size can impact the effectiveness of both by 1) partially defining the hydraulic conductivity of the stratum, and effectively constraining advection; and 2) controlling the amount of surface in contact among the se- 
diment particles, thereby limiting conduction. Vaux [23] and Cooper [24] suggest that larger objects in or on the streambed surface respectively alter the flow paths of hyporheic and stream waters. With respect to finer sediments, Ringler and Hall [25] showed that the largest gradients between stream and hyporheic water temperatures occur at heavily silted sites, where slow flows persist. Additionally, variations in hydraulic conductivity of the streambed may result in uneven discharge and flow geometry [26].

This study focuses on variations in temperature profiles of the $\mathrm{HZ}$ at two sites: a gravel dominated $\mathrm{HZ}$ and a sand dominated $\mathrm{HZ}$, with the hope of furthering existing knowledge of water temperature in the environment and providing another tool for characterizing HZs. The use of time-series analysis allows the identification of data trends otherwise concealed. A similar statistical based approach taken by Malard et al. [6] successfully assessed temperature patterns within a glacial floodplain system. Specific interests lie in transmission of both seasonal and diel surface temperature signals into the subsurface, the comparison of lateral and longitudinal temperature profiles, and the possibility of quantitatively delineating the $\mathrm{HZ}$ using temperature data.

\section{Study Site}

Field investigations focused on two sites along a stretch of the Little Kickapoo Creek (LKC) running through the Illinois State University Randolph Well Field (Figure 1),

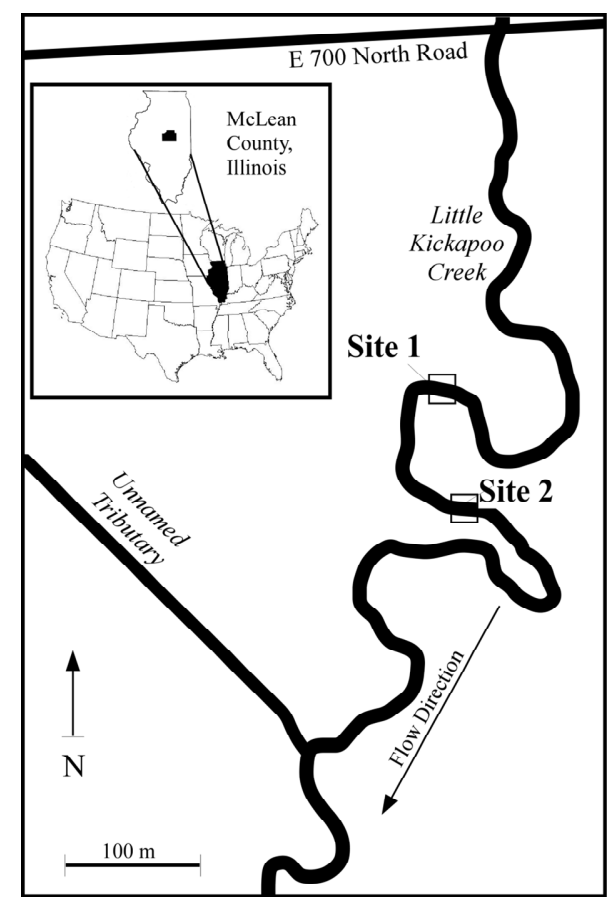

Figure 1. Location of the two study sites within little kickapoo creek inset shows the location within the USA. located in McLean County, central Illinois, USA. Central Illinois has a temperate climate, with cold, snowy winters and hot, wet summers. Mean annual air temperature for the period from 1950 to 2002 was $11.2^{\circ} \mathrm{C}$ [12].

The site has been described by Peterson and Sickbert [12] and presented here are the relevant data.Originating in an urban area approximately $11 \mathrm{~km}$ north of the study site, LKC is a low gradient third-order perennial stream that meanders (sinuosity of 1.8) through Wisconsinan glacial plains. Regionally LKC is a gaining stream, with a gradient of 0.002. Locally, the meander containing the two study sites has a gradient of 0.003 . The reach under investigation is unmodified and meanders through an approximately $300 \mathrm{~m}$ wide alluvial valley. Land bordering the stream is predominantly used for agriculture.

Three geologic units comprise the alluvial valley through which LKC meanders: the Wedron Formation, the Henry Formation, and the Cahokia Formation (listed from oldest to youngest). Being a clay-rich low-permeability till, the Wedron Formation acts as a lower confining unit to the Henry Formation. Within the outwash valley, the Henry Formation functions as an aquifer due to its poorly sorted gravels and sands, having an average hydraulic conductivity of $10 \mathrm{~m} /$ day and an average thickness of $5-7 \mathrm{~m}$. Above the Henry Formation lies the Cahokia Formation, consisting of fine-grained sand and mud, with a thickness of up to $2 \mathrm{~m}$. The LKC channel is inset into the Cahokia Formation, cutting into the top of the Henry Formation. LKC streambed sediments are composed of mostly Henry Formation materials, consisting primarily of gravel and coarse sand with interstitial silt. Surface sediments vary with distance along the channel.

Both sites are located in riffle sections of the stream channel. Site 1 is the further upstream site, featuring predominantly gravel, greater than $2 \mathrm{~mm}$, while Site 2 lies further downstream with predominantly sand size sediments $(0.0625 \mathrm{~mm}$ to $2 \mathrm{~mm})$. Particles larger than $2 \mathrm{~mm}$ comprise $61 \%$, sand accounts for $36 \%$ and silts and clays are $3 \%$ of the material at Site 1 . Overall the median particles size (d50) at Site 1 is $3.9 \mathrm{~mm}$. At Site 2, sand size particles are dominant, comprising $62 \%$ of the material. Gravel account for $36 \%$ and $2 \%$ are silts and clays, resulting in a median particles size (d50) of $0.94 \mathrm{~mm}$ at Site 2. Based upon grain size, the hydraulic conductivity $(\mathrm{K})$ at Site 1 is $4.60 \mathrm{~cm} / \mathrm{s}$ and at Site 2 is $0.02 \mathrm{~cm} / \mathrm{s}$ [12].

\section{Methodology}

\subsection{Temperature Measurements}

Identical temperature probe grids were set up along riffles at two LKC sites. Each grid consisted of five vertical logger nests (referred to as wells) creating both lateral and longitudinal profile lines across the channel. The two 
profile lines intersected roughly in the stream's thalweg, where one nest provided data for both profiles (Figure 2(a)). Within each $6.35 \mathrm{~cm}$ PVC well, temperature loggers were positioned at depths of $30 \mathrm{~cm}, 60 \mathrm{~cm}, 90 \mathrm{~cm}$, and $140 \mathrm{~cm}$ (Figure 2(b)). To partition off the different depths and to reduce vertical mixing, foam sealant was used and the wells were capped. At each depth, two 12.7 $\mathrm{mm}$ diameter holes drilled into the walls at each depth provided connection to the matrix. Two additional temperature loggers recorded surface water temperatures. $\mathrm{HOBO}^{\circledR}$ StoyAwayTidbiT Temperature Loggers with an accuracy of $\pm 0.2^{\circ} \mathrm{C}$ and a resolution of $0.16^{\circ} \mathrm{C}$ at $20^{\circ} \mathrm{C}$ were used in this work. All loggers were programmed to record temperatures at 15-minute intervals. Data collection started on the June 30, 2007 and ended on the December 10, 2007, when all loggers were removed from the substrate. A complementing study examined the amount of scour and fill at each location during the study period. No scour and fill event greater than $10 \mathrm{~cm}$ occurred during the period of monitoring.

Additional data collection included stream stage and air temperature. The stream stage was recorded at a

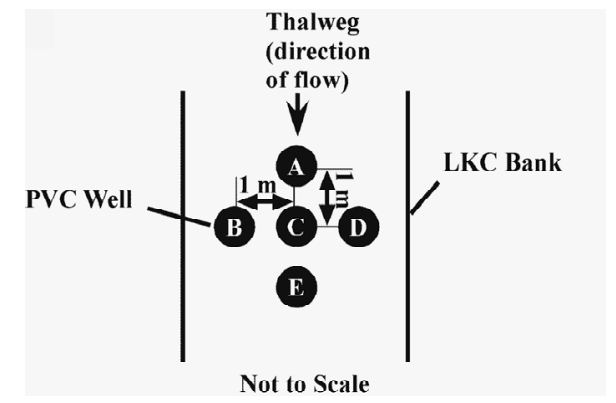

(a)

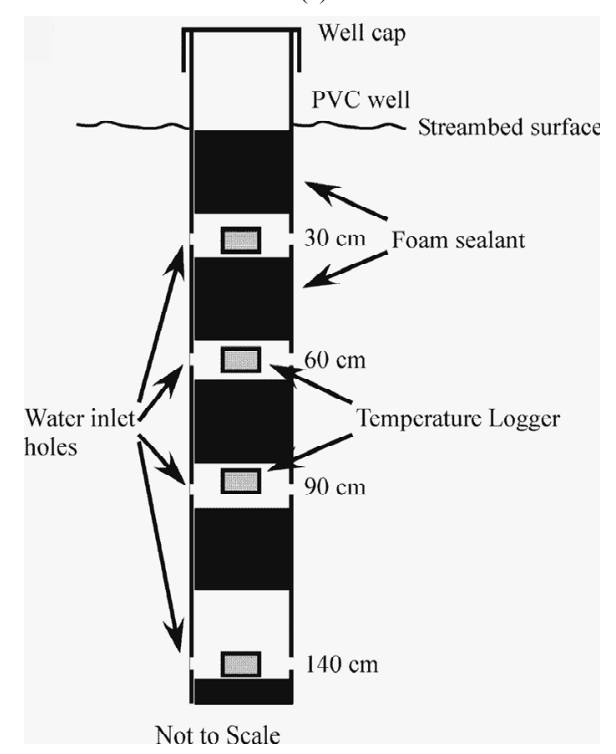

(b)

Figure 2. (a) Birds-eye view of well setup in the stream channel; (b) Detailed view of individual well design. permanent stilling-well located $20 \mathrm{~m}$ upstream of Site 1. Air temperature was obtained from a weather station 220 $\mathrm{m}$ away. Both stream stage and air temperature were recorded on a 15-minute interval.

During the data collection period, several unforeseen problems were encountered. Temperature loggers located at $1 \mathrm{~A}-90 \mathrm{~cm}, 1 \mathrm{E}-90 \mathrm{~cm}, 2 \mathrm{~B}-90 \mathrm{~cm}$, and 2D-90 cm failed completely. Furthermore, due to extensive beaver dam construction upstream of both sites, stream flow intermittently became unmeasureable from approximately August 2, 2007 to October 1, 2007, resulting in low flow conditions at both Site 1 and Site 2. The temperature effects of this can be seen in Figure 3. Initially, Site 2 surface stream temperatures closely mimic Site 1 surface stream temperatures. However, near the beginning of August, Site 2 surface stream temperatures show an increase in diel amplitude, approximating the variability of daily air temperatures. Additionally, surface stream temperatures at Site 2 are warmer than at Site 1, beginning near October 1, 2007. This temperature difference is likely due to a greater insolation at Site 2 once trees begin to lose their foliage.

\subsection{Statistical Methods}

For all statistical calculations, 15 -minute $(\mathrm{n}=15711)$ or hourly $(n=3904)$ temperature values from June 30, 2007 to December 10, 2007 were used. Statistical analyses were conducted using SPSS version 16.0 [27].

Using 15-minute data, box plots were created for both the summer (June 21, 2007 to September 23, 2007) and autumn (September 24, 2007 to December 22, 2007) seasons (defined by the use of equinoxes and solstices, which coincided with the temperature reversal), although data for both periods are incomplete. Summer collection started late on June 30, 2007 while autumn collection ended early on December 10, 2007 due to a stream log-

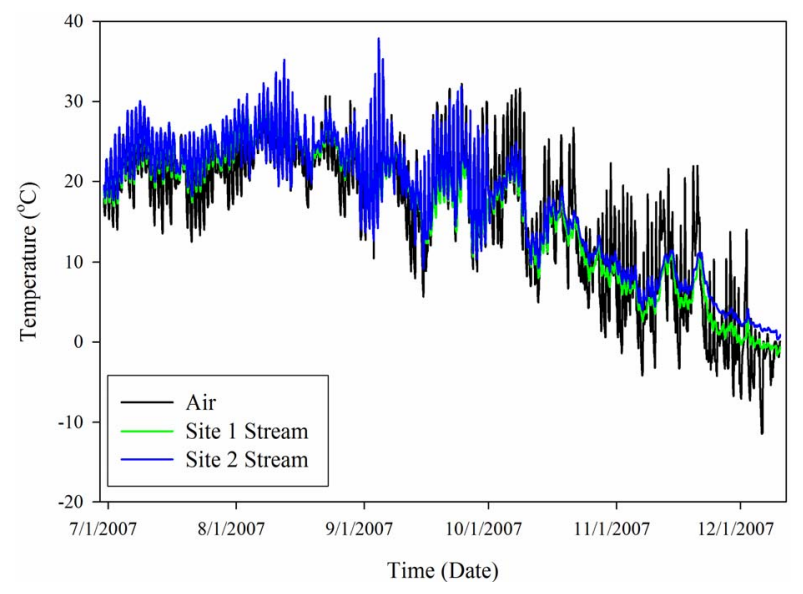

Figure 3. Air and stream (Site 1 and Site 2) temperature 15-minute incrementing time series for entire data collection period. 
ger failure. The temperature reversal (an isothermal period during which air temperatures change from warm to cool) occurring in early autumn, requires the separation into seasons for unbiased summary statistics, and though neither season is fully complete, the separation into seasons gives a more illustrative overview of temperatures than a grouped approach.

Time series cross-correlation, as described by Mangin [20], was used to understand the relationships between streambed temperatures within each site, as well as between sites in more detail.Time series cross-correlation measures the relationship between two quantitative time series, i.e. surface water temperature compared to hyporheic water temperature.The observations of two series are correlated as various lags and leads, where the relationship is expressed by a cross-correlation coefficient $(r)$ equal to a value between -1 and 1 , with values closest to 1 indicating the strongest relationship between the time series.

The cross correlation coefficient $(r)$ was obtained using the formula proposed by Jenkins and Watts [28] and as used by Malard et al. [6] to analyze streambed time series temperature data:

$$
r_{+k}=\frac{C_{x, y(k)}}{S_{x} S_{y}}
$$

With

$$
\begin{gathered}
C_{x, y(k)}=n^{-1} \sum_{i=1}^{n-k}\left(x_{i}-\bar{x}\right)\left(y_{i+k}-\bar{y}\right) \\
r_{-k}=\frac{C_{x, y(k)}}{S_{x} S_{y}}
\end{gathered}
$$

With

$$
C_{x, y(k)}=n^{-1} \sum_{i=1}^{n-k}\left(y_{i}-\bar{y}\right)\left(x_{i+k}-\bar{x}\right)
$$

with $x_{1}, x_{2}, \cdots, x_{n}=$ hourly values of surface water temperature or temperatures, at shallower depths; $y_{1}$, $y_{2}, \cdots, y_{n}=$ hourly values of hyporheic water temperature or temperatures at deeper depths; $k=0,1,2, \cdots, m$ where $k$ is equal to the lag, and $m$ is equal to the maximum number of lags. $\bar{x}$ and $\bar{y}$ are means and $S_{x}$ and $S_{y}$ are the means andthe standard deviations of the respective $x$ and $y$ series.

For the evaluation of cross-correlation, the dataset was reduced to hourly data to decrease the number of data and to reduce the possibility of over-fitting the statistical model. For the comparison of seasonal trends of both surface water and hyporheic water temperatures a 24hour moving filter was applied to hourly data prior to cross-correlation, removing diel temperature fluctuations. Each filtered temperature at time $t$ equaled the average temperature from 12 hours prior to and 12 hours after time $t$ (including the temperature at time $t$ in the ave- raging).

For computation of between-site comparisons, gradients (the difference between surface water temperatures and temperatures at $140 \mathrm{~cm}$ depth) were used for cross-correlation in substitution of actual recorded temperatures. This eliminated the influence of differing surface stream temperatures, and allowed instead a comparison of the degree of temperature change with depth between sites.

First-order differencing was applied to all time series prior to cross-correlation, removing the data's temporal trend component and reducing autocorrelation. First-order differencing is achieved by subtracting from each term of the original series the preceding term. The transformation generates a new series defined by: $\hat{X}_{t}=\left(X_{t}-X_{t-1}\right)$ where $\hat{X}_{t}=$ term of the filtered time series, and $X_{t}=$ term of the original time series. All cross-correlations were computed using a lag $(\mathrm{k})$ of $1 \mathrm{hr}$, and a maximum number of lags (m) of 125 determined so that $m \times k$ is less than or equal to $\mathrm{n} / 3$ as recommended in the literature [20].

For the evaluation of cross-correlation results, correlation coefficients $(r)$ equal to or greater than 0.2 were treated as statistically significant. This was determined based on the number of observations used, and assuming rejection of the null hypothesis (there is no difference) if $\mathrm{a}>0.01$.

\section{Results}

\subsection{Summary Statistics}

A distinct difference in temperature patterns is seen when comparing summer and autumn results (Figure 4). In summer, mean streambed temperatures fall at or below mean surface stream temperatures, and pronounced cooling is witnessed with depth into the streambed at both sites. In autumn, these patterns are reversed with mean surface stream temperatures at or below mean streambed temperatures. A slight warming trend is also observed in mean streambed temperatures with depth. Additionally, temperatures appear more homogenized top to bottom, where mean temperatures at increasing depths are not distinctly different. It can be projected that the degree of difference of autumn to summer temperature patterns would increase in winter, and decrease again in spring with the next reversal. Irrespective of the differences observed between summer and autumn temperatures, a decrease in temperature ranges with streambed depth is experienced universally to varying degrees. In general, the observations above show the data from this study to be in line with general patterns witnessed in other HZ temperature studies, such as by Dogwiler and Wicks [15], in a karst environment featuring similar stream sediments as at Site 1, and by White et al. [16] in a Michigan river. 


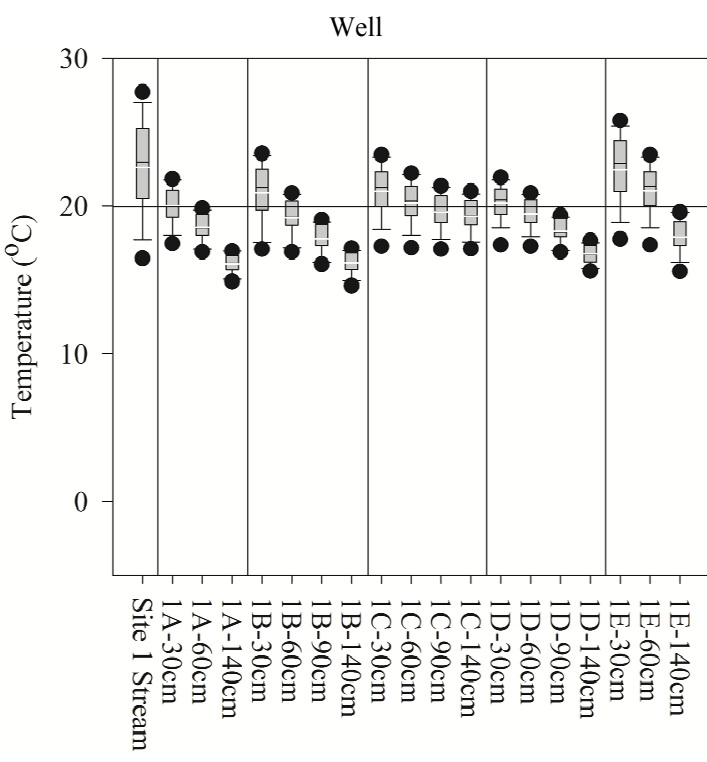

(a) Site 1 summer

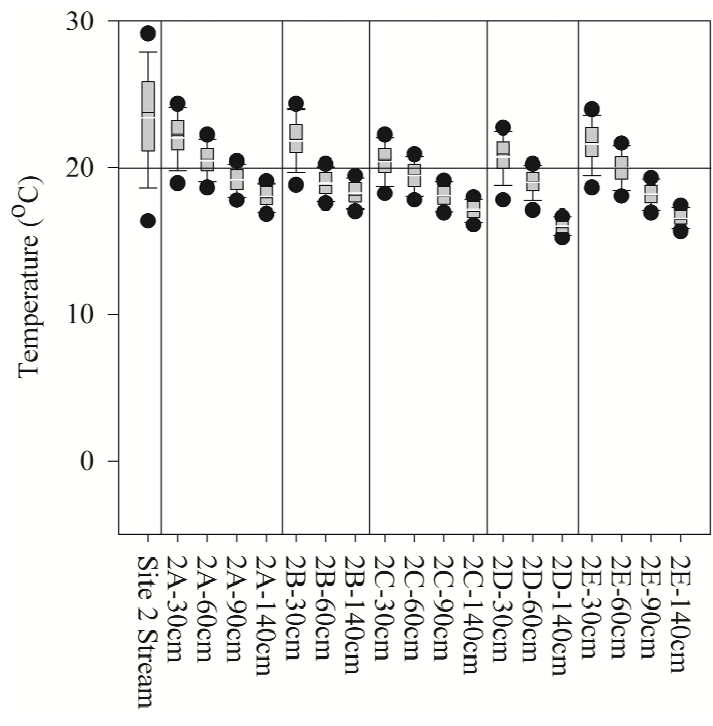

(b) Site 2 summer

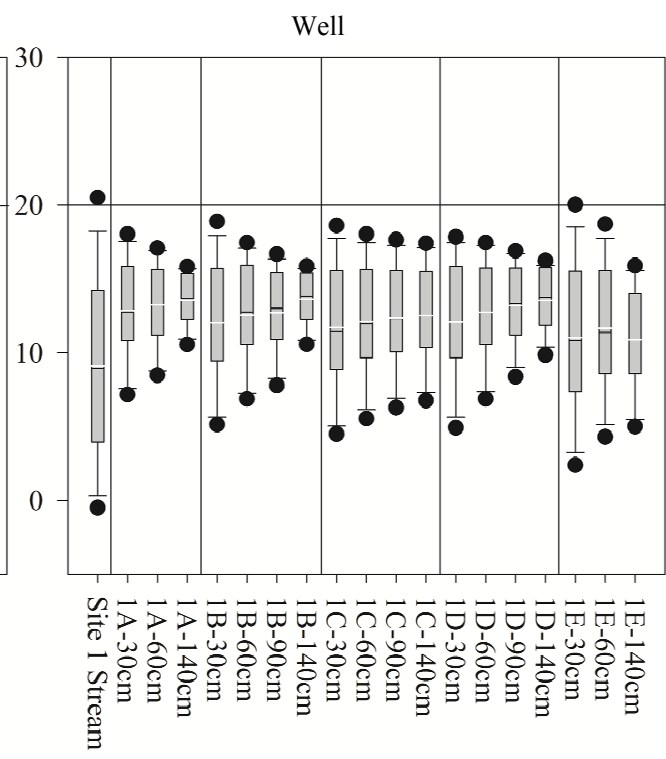

(c) Site 1 fall

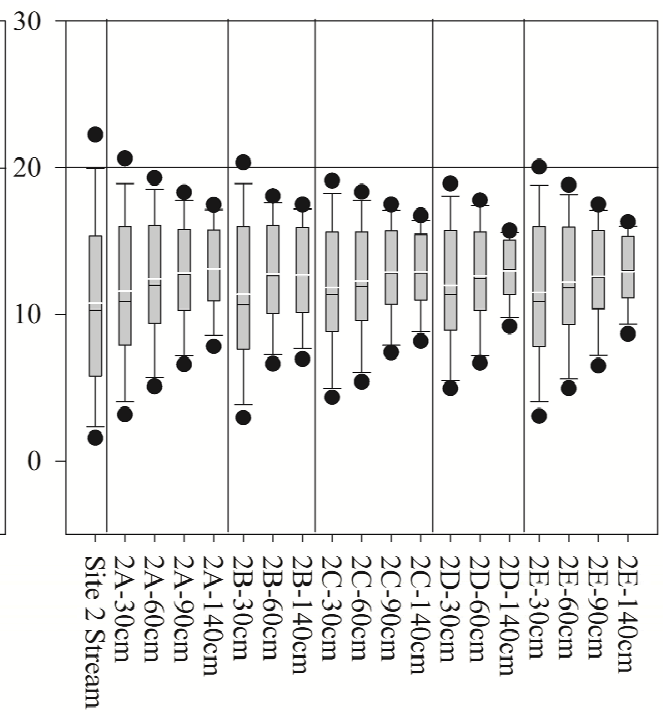

(d) Site 2 fall

Figure 4. Box plots of temperature data with reference lines at $20^{\circ} \mathrm{C}$. The edges of the boxes represent the 25 th and 75 th percentiles with the black line at the median and the white line at the mean; the whisker bars depict the 10th and 90th percenttiles and the dots represent the 5th and 95th percentiles. (a) Site 1 summer (June 21, 2007 to September 23, 2007); (b) Site 2 summer (June 21, 2007 to September 23, 2007); (c) Site 1 autumn (September 24, 2007 to December 22, 2007); (d) Site 2 autumn (September 24, 2007 to December 22, 2007).

A site comparison of summer box plots reveals more uniform temperature decreases with increasing streambed depth in each well at Site 2. At Site 1, wells 1C and 1E have greater temperature ranges persisting at depth, suggesting that wells $1 \mathrm{C}$ and $1 \mathrm{E}$ maintain effective temperature transmission at depth. Additionally, Site 2 surface stream temperatures vary over a wider temperature range than at Site $1(\mathrm{t}(3903)=-67.98, p<0.01)$, experiencing more days when temperatures are warmer, (up to a maximum temperature of $38^{\circ} \mathrm{C}$ ). Interestingly however, Site 2 streambed temperatures do not noticeably reflect this increased temperature range.

A site comparison of autumn box plots reinforces summer box plot observations. Temperatures in wells $1 \mathrm{C}$ and $1 \mathrm{E}$ again maintain larger temperature ranges at depth than do other wells at Site $1(\mathrm{t}(1851)=-92.84, p<0.01)$. Surface stream temperatures at Site 2 again experience warmer temperatures, presumably due to the remainder of the low-flow period as well as to generally warmer temperatures in late autumn due to increased insolation. Surprisingly, Site 2 wells experience smaller temperature ranges than do equivalent Site 1 wells, suggesting slower 
transmission of surface temperatures into the streambed.

\subsection{Seasonal Cross-Correlation}

Results of the 24-hour averaging filter applied to well $1 \mathrm{E}$ and $2 \mathrm{E}$ (Figure 5) are representative of filter applications to all other wells. The greatest impact is on time series that feature strong diel components, such as surface stream temperatures. Temperatures at depth within the streambed were only mildly affected by the filter, due to their already dampened diel signals. Both a seasonal trend and short-term, 1 to 3 day, thermal fluctuations are observed in the filtered time series, closely matching the findings of Malard et al. [6].

All streambed temperatures show significant correlation to the seasonal trends in stream water (Figure 6). As expected, correlations between temperatures at $30 \mathrm{~cm}$ depth and stream water are highest within each well. The correlation coefficient generally decreased with depth into the streambed, as distance from the stream increases, and temperature signals become dampened through the mixing with groundwater. These results are as expected, based on research by Stonestrom and Constantz [4] amongst others, though not evaluated by cross-correlation.

With increasing depth in the streambed, temperature signals continue to be significantly correlated with seasonal trends in stream water over longer lag periods. This is likely due to the greater thermal homogeneity at depth, as illustrated in the filtered data (Figure 5). The filtered data at depth $140 \mathrm{~cm}$ is relatively insensitive to short-

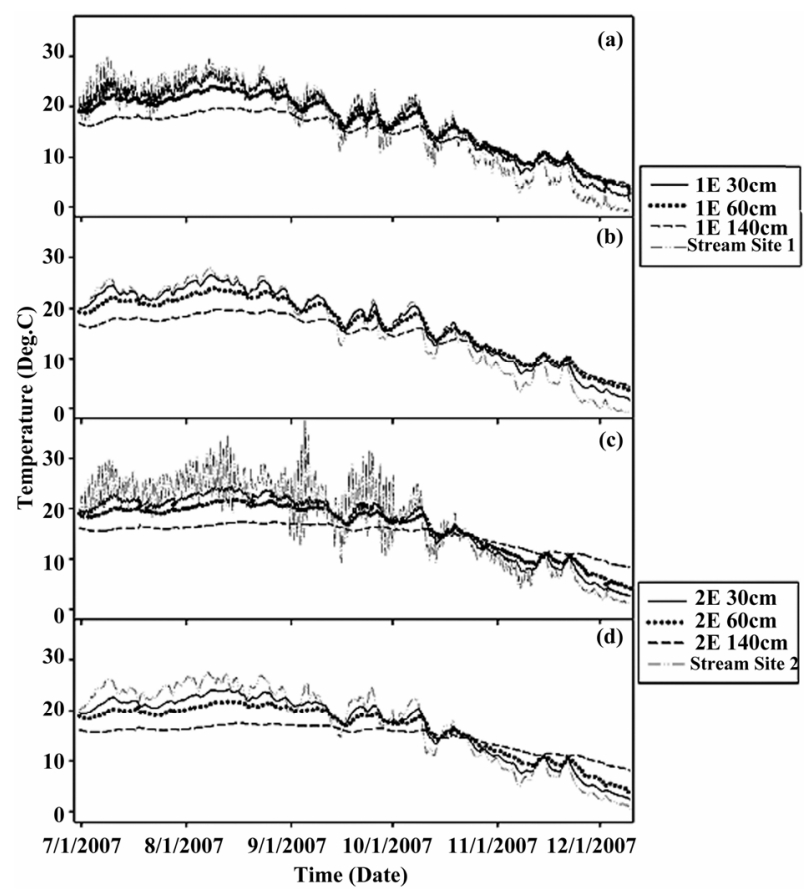

Figure 5. Comparison of unfiltered hourly time series (a) and (c) and filtered hourly time series (b) and (d) of wells $1 \mathrm{E}$ and $2 \mathrm{E}$, respectively. term surface thermal fluctuations, resulting in lower correlation coefficients. However, temperatures remain more constant at $140 \mathrm{~cm}$ depth. Thus, a significant yet low correlation value persists for longer periods.

Lag times (the point where the highest correlation coefficient along a single curve is obtained) of seasonal trends increase with depth to varying degrees, differing between sites as well as among individual wells. Seasonal lag times at $30 \mathrm{~cm}$ depth at Site 1 range from $5 \mathrm{hrs}$ $(r=0.941)$ to $23 \mathrm{hrs}(r=0.41)$, and at Site 2 from $8 \mathrm{hrs}(r$ $=0.721)$ to $18 \mathrm{hrs}(r=0.575)$. At $140 \mathrm{~cm}$ depth, seasonal lag times at Sites 1 and 2 ranged from $32 \mathrm{hrs}(r=0.633)$ to $109 \mathrm{hrs}(r=0.279)$ and $56 \mathrm{hrs}(r=0.29)$ to $68 \mathrm{hrs}(r=$ 0.312 ), respectively. At $30 \mathrm{~cm}$, relative heterogeneity of lag times is observed at both sites. However, at $140 \mathrm{~cm}$ depth, lag time heterogeneity persists only at Site 1, while Site 2 displays relatively uniform seasonal lags.

To further the understanding of subsurface connections, while also providing a means for lateral and lon-

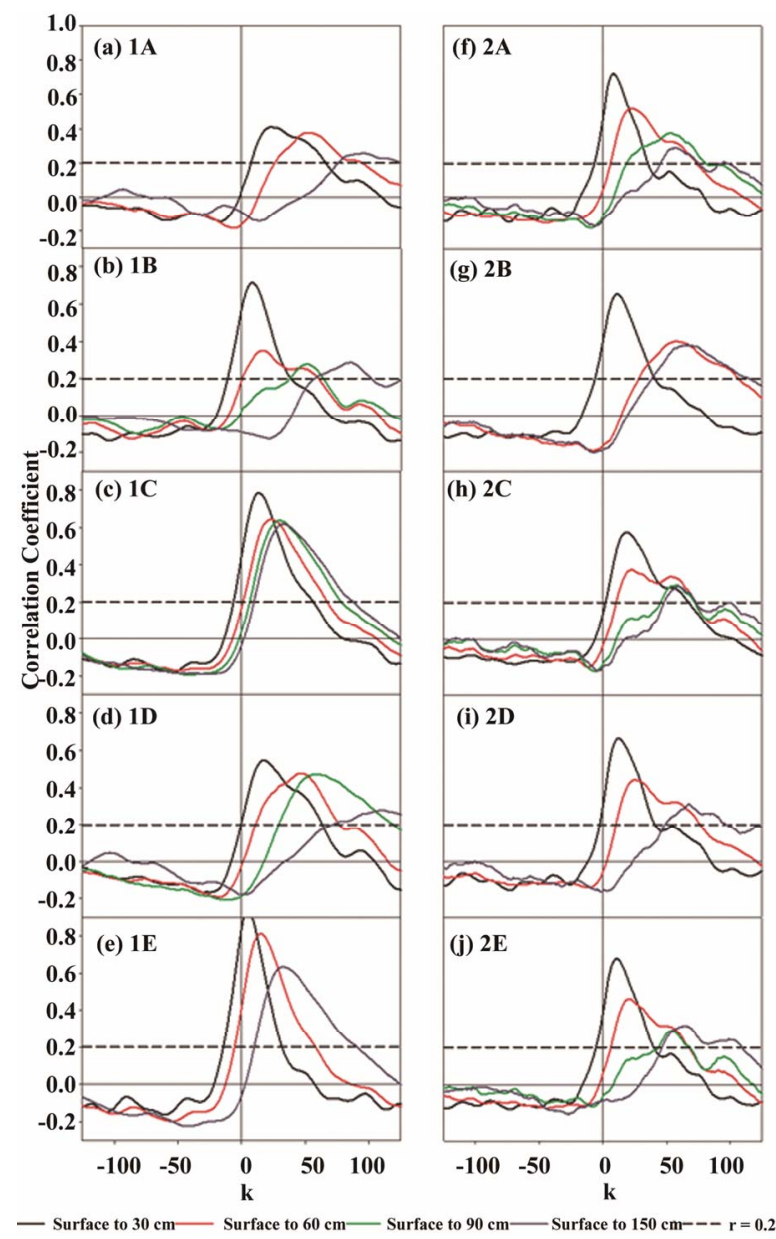

Figure 6. Cross-correlograms per well, showing correlation between hourly, filtered ( 24 hrs averaging filter and first order differencing) time series of surface stream temperatures and depths 30, 60, 90 and $140 \mathrm{~cm}$ within the streambed at Site 1 (a)-(e) and Site 2 (f)-(j). 
gitudinal profile comparison, seasonal temperature trends were compared at each site by cross-correlation at equal depths along both profile lines (Figure 7). In general, as depth within the streambed increases, the correlation coefficient between temperatures at each depth decreases, regardless of profile type or site (Figure 7). One exception exists, between temperatures at wells $1 \mathrm{C}$ and $1 \mathrm{E}$. Previously identified as featuring unique temperature patterns.

A second generalization can be made when comparing lateral and longitudinal profiles of Sites 1 and 2. Site 1 correlograms show great variation in peak $r$ values, both between depths and at the same depth. When referring back to Figures 4(a) and (b), both wells $1 \mathrm{C}$ and $1 \mathrm{E}$ showed wider temperature ranges than wells $1 \mathrm{~A}, 1 \mathrm{~B}$, and $1 \mathrm{D}$ at $140 \mathrm{~cm}$ depth, indicating a greater influence of surface water temperatures within the streambed at these locations. Additionally, in well $1 \mathrm{C}$ the $90 \mathrm{~cm}$ and $140 \mathrm{~cm}$ depths have almost equal mean temperatures throughout the summer season. In contrast, wells 1A, 1B, and 1D show more regularly decreasing temperature ranges and mean temperatures with depth. Laterally at depth $140 \mathrm{~cm}$,

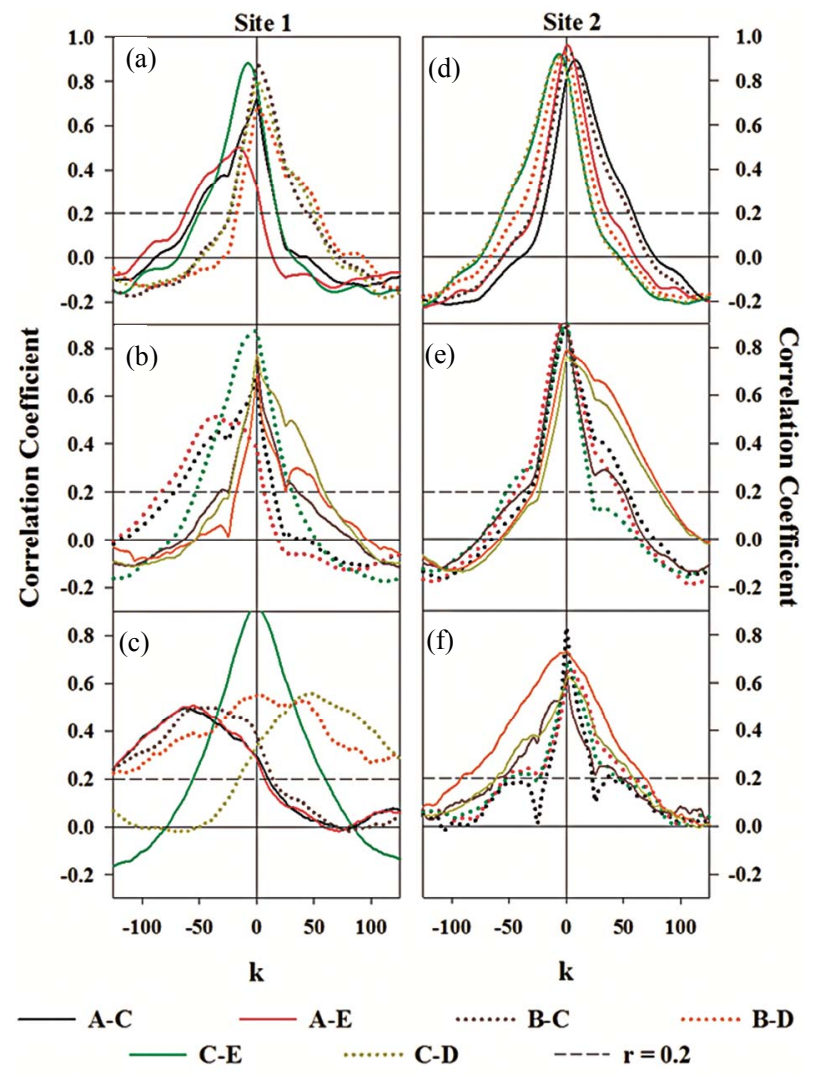

Figure 7. Cross-correlograms showing correlation between hourly filtered (24 hrs averaging filter and first order differencing) time series between wells along longitudinal (solid lines) and lateral (dottedlines) profiles. (a) Site 1, $30 \mathrm{~cm}$; (b) Site 1, $60 \mathrm{~cm}$; (c) Site 1, $140 \mathrm{~cm}$; (d) Site 2, $30 \mathrm{~cm}$; (e) Site 2, $60 \mathrm{~cm}$; and (f) Site 2, $140 \mathrm{~cm}$. seasonal trends in wells $1 \mathrm{~B}$ and $1 \mathrm{D}$ lag behind well $1 \mathrm{C}$, while longitudinally only seasonal trends in well 1A lag behind well $1 \mathrm{C}$. At $140 \mathrm{~cm}$ seasonal trends in wells $1 \mathrm{C}$ and $1 \mathrm{E}$ are highly correlated. In contrast, Site 2 correlograms (Figures 7(d)-(f)) consistently peak at or very near $\mathrm{k}=0$. This is supported by the patterns seen in Figures 4(c) and (d), where summer temperature ranges and mean temperature patterns change relatively uniformly across Site 2 .

As for a comparison between lateral and longitudinal profiles within a single site, no universal patterns were detected. Local variability in streambed flow patterns and materials likely causes observed differences, with a high degree of unpredictability.

\subsection{Diel Cross-Correlation}

Significant correlation between diel stream and streambed temperatures is seen at 2 wells at Site 1, and at 4 wells at Site 2 (Figure 8). Additionally, with the exception of well $1 \mathrm{E}$, significant correlation is seen only between stream and $30 \mathrm{~cm}$ depth temperatures. In well $1 \mathrm{E}$, significant correlation is also seen between stream and 60 $\mathrm{cm}$ depth temperatures. Lag times of diel temperatures at Sites 1 and 2 range from $3 \mathrm{hrs}(r=0.3110)$ to $9 \mathrm{hrs}(r=$ $0.3650)$ and $6 \mathrm{hrs}(r=0.5030)$ to $8 \mathrm{hrs}(r=0.3260)$ respectively. The trend of greater thermal variability at Site 1 persists in the diel temperatures.

As with seasonal temperature trends, diel temperature trends were analyzed along lateral and longitudinal profile lines across each site (Figure 9). At Site 1 significant correlation occurs at both $30 \mathrm{~cm}$ and $60 \mathrm{~cm}$ depth at $k=0$. Correlation between wells $1 \mathrm{C}$ and $1 \mathrm{E}$ at $30 \mathrm{~cm}$ depth is unique in that it shows significant 24-hour fluctuations. This is likely the effect of their diel temperature trends correlating. Interestingly, diel patterns in well 1C lag behind those experienced in well $1 \mathrm{E}$ by 5 hours, despite well $1 \mathrm{C}$ being situated 1 meter upstream of well $1 \mathrm{E}$. This pattern of temperature change opposing the direction of stream flow could indicate preferential flow paths at Site 1 .

At Site 2 all wells show significant correlation between diel temperature patterns at $30 \mathrm{~cm}$ depth, displaying the unique 24-hour cycle. At depths $60 \mathrm{~cm}$ and $140 \mathrm{~cm}$ however, significant correlation exists only at $\mathrm{k}=$ 0 .

\section{Discussion}

\subsection{Role of Surface Waters}

Surface waters are the source of increased temperature ranges and variability within the $\mathrm{HZ}$, as both diel and seasonal temperature patterns are transmitted [13,29]. In contrast, groundwater, when mixed with surface water, has a dampening effect on diel temperature patterns 


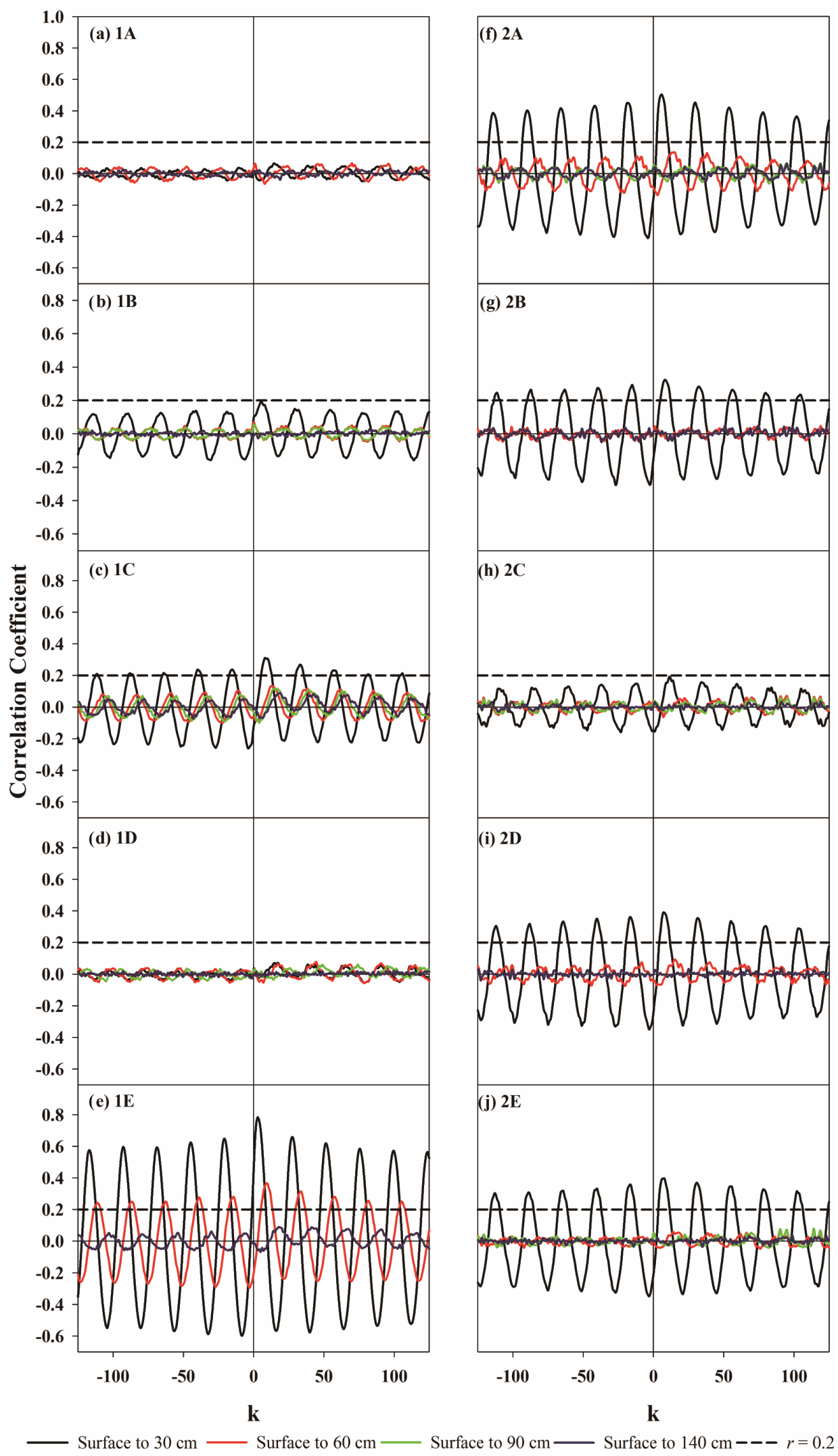

Figure 8. Cross-correlograms per well (indicated by letters A through E), showing correlation between hourly transformed (first order differencing) time series of surface stream temperatures and depths 30, 60, 90 and $140 \mathrm{~cm}$ within the streambed at Site 1 (a)-(e) and Site 2 (a)-(e). 


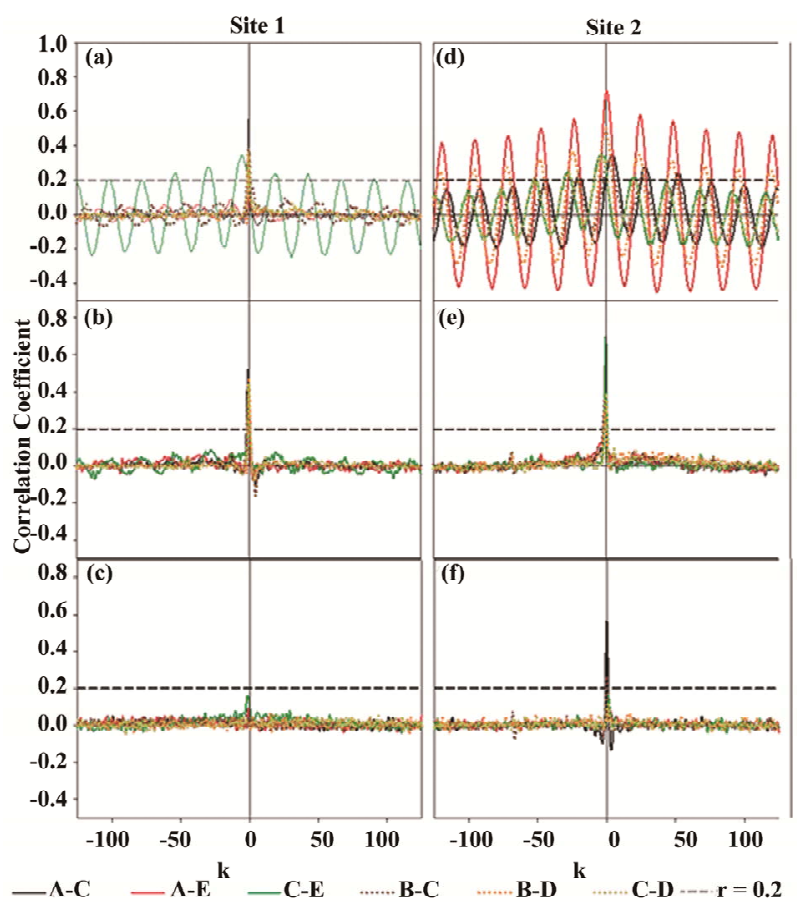

Figure 9. Cross-correlograms at $30 \mathrm{~cm}(\mathrm{a})$ and (d), $60 \mathrm{~cm}(\mathrm{~b})$ and (e), and $140 \mathrm{~cm}$ (c) and (e), showing correlation between hourly transformed (first order differencing) time series between wells along longitudinal (solid lines) and lateral (dotted lines) profiles at Site 1 and Site 2, respectively.

within the $\mathrm{HZ}$, as it imparts only seasonal temperature trends $[4,13]$. The decreasing temperature ranges and mean temperatures, as seen in box plots (Figure 4), can be attributed to the mixing of surface and groundwater and the increasing influence of groundwater with depth.

\subsection{Differences between Site 1 \& Site 2}

Box plots reveal that while the stream water at Site 2 experienced greater temperature extremes than at Site 1, the extremes were not observed in the streambed temperatures at Site 2. This suggests that hyporheic exchange is lower at Site 2 than at Site 1. Possible explanations include the allowance of less surface water infiltration, the presence of increased groundwater discharge, the presence of meander flow-through, or perhaps the retardation of infiltration velocities associated with the finer grain sizes of the substrate at Site 2 as suggested by Ringler and Hall [25]. The hypothesis of less surface water infiltration is tied to the discharge of a greater groundwater component, dampening diel surface water signals. This possible explanation is consistent with the establishment of Site 2 as a gaining reach. The second possibility of retarded infiltration velocities is supported by Ringer and Hall [25], who found larger temperature gradients between stream and hyporheic waters at heavily silted sites, due to slower inter-gravel flows. Based on grain size analyses, we believe that while silt size particles are not prevalent at Site 2, the small particles sizes and lower hydraulic conductivity, as compared to Site 1, may exert a similar effect. Though dampened in amplitude, diel surface water signals are still transmitted down to a $30 \mathrm{~cm}$ depth almost universally across Site 2 (Figure 9).

In addition to increased dampening of surface thermal trends, greater uniformity in thermal trends is seen in box plot and cross-correlation results at Site 2. Thus, Site 2 has more uniform $\mathrm{HZ}$ flow path patterns associated with more homogeneous sediment distribution. Vaux [23] and Cooper [24] observed that larger objects in or on the streambed surface respectively, cause significant disruptions to HZ flow paths and thereby thermal patterns as well, which does not appear to be the case at Site 2. Site 1 however, displays distinct thermal heterogeneity when comparing thermal trends in wells $1 \mathrm{~A}, 1 \mathrm{~B}$, and $1 \mathrm{D}$, to those in wells $1 \mathrm{C}$ and $1 \mathrm{E}$, making the presence of sediment variations a possibility. While no large particles were observed on the streambed surface, Buyck [30] documented the presence of till anomalies in the stream bed up to depths of $60 \mathrm{~cm}$.

Numerical modeling of the area indicated that Site 1 is a downwelling zone, while Site 2 is an upwelling zone [31]. While the site-specific details are not addressed, these flow dynamics potentially explain many of the trends observed in the statistical results of this study, as outlined below.Advection, as involved in a losing reach or downwelling zone, is commonly considered the most effective means of thermal transport, as fluid movement is typically faster and more efficient at heat transmission than the process of conduction. Therefore, the effective transmission of diel temperature signals into the substrate is likely due to advection of stream water into the HZ. This goes hand-in-hand with the established temperature-based method of defining losing and gaining reaches of a stream, where the presence of increased diel signal transmission into the $\mathrm{HZ}$ is an indication of a losing reach [4].

Lags between unfiltered hourly temperatures of the stream and at $30 \mathrm{~cm}$ depth (showing diel temperature variations) ranged from 3 to 9 hours. The smallest lag of 3 hours was experienced at Site 1, where sediments are coarser and feature a higher hydraulic conductivity. Site 2 , with a lower hydraulic conductivity, experienced lags of 6 to 8 hours.

The persistent penetrations of diel surface water temperature patterns to depths of $30 \mathrm{~cm}$ in wells $1 \mathrm{C}$ and $1 \mathrm{E}$, and to a depth of $60 \mathrm{~cm}$ (Figure 8) in well 1E, suggest the influence of a strong vertical advective component at Site 1. Additionally, these trends reinforce the identification of Site 1 as a downwelling zone, and pinpoint wells $1 \mathrm{C}$ and $1 \mathrm{E}$ as the point of most focused down- 
welling of surface water to a minimum depth of $30 \mathrm{~cm}$ in both wells, and to a minimum depth of $60 \mathrm{~cm}$ in well $1 \mathrm{E}$. This is further reinforced by seasonal correlation coefficients of surface water to $140 \mathrm{~cm}$ depth remaining above 0.6 at both wells $1 \mathrm{C}$ and $1 \mathrm{E}$, suggesting that surface water seasonal variations are responsible for $60 \%$ of the seasonal variability witnessed at this depth. It is therefore likely that advection penetrates deeper than the minimum values stated above, yet based on the available data no conclusive statement can be made.

Though both wells $1 \mathrm{C}$ and $1 \mathrm{E}$ appear to be the location of deepest surface water penetration, well $1 \mathrm{E}$ is the location of fastest surface water penetration to a depth of $30 \mathrm{~cm}$, as shown by correlation results between $30 \mathrm{~cm}$ temperatures in wells $1 \mathrm{C}$ and $1 \mathrm{E}$. Flow paths within the $\mathrm{HZ}$ and streambed can be controlled by a large number of factors. However, from what is known of Site 1 regarding sediment particle size and thermal heterogeneity, it is very likely that both flow paths and thermal regimes are impacted by sediment heterogeneities in the $\mathrm{HZ}$ and streambed. Buyck [30] found gray clay in the streambed, originating possibly from collapsed cut banks, or from underlying till layers. Such clay in the HZ would act as barriers to advection, and increase the chance of preferential flow path development, which could in turn lead to uncharacteristic flow patterns, as supported by research conducted by Vaux [23] and Becker et al. [26].

Site 2 flow path delineation is somewhat less precise than at Site 1. The comparison of lateral and longitudinal profiles at $30 \mathrm{~cm}$ depth reveals that the strongest correlation exists in the longitudinal direction, following the direction of stream flow. However, correlation between lateral temperature patterns at $30 \mathrm{~cm}$ depth exists also. This correlation reflects similar degrees of surface diel signal penetration to $30 \mathrm{~cm}$ depth. At depths greater than $30 \mathrm{~cm}$, correlation of diel patterns is only significant at $k$ $=0$, suggesting lateral homogeneity of temperatures across the site. Based on statistical results, we believe flow paths at Site 2 are mostly in the longitudinal direction, at low velocities, and active surface water infiltration is limited to the upper $30 \mathrm{~cm}$ of the streambed. The influence of lateral flow is supported by the numerical modeling of Van der Hoven [31] showing the area to be an outlet for flow from underneath a meander lobe.

\subsection{Controls on Thermal Transport}

The process of conduction, while in part dependent on the thermal properties of a medium, is driven by temperature gradients, where steeper temperature gradients increase the effectiveness of conduction. Steepest temperature gradients appear to exist laterally at Site 1 , between vertically down-welling warmer temperatures in well $1 \mathrm{C}$ and $1 \mathrm{E}$, and cooler temperatures in wells $1 \mathrm{~A}, 1 \mathrm{~B}$, and 1D. Subsequently, conduction may be an important mode of heat transport in the lateral direction at Site 1. At Site 2 thermal gradients appear more gradual, suggesting conduction will be kept to a minimum. However, during the low-flow period at Site 2, the heating of streambed sediments by solar radiation may have provided a steep thermal gradient, allowing conduction an active role in the transport of heat into the HZ. A similar proposition was put forward by Shepherd et al. [32]. However, there are situations where advection and vertical conduction are of similar magnitude [22].

Quantitative delineation of the HZ based on thermal trends has not been possible. Though statements can be made as to where the $\mathrm{HZ}$ definitely persists, such as at 30 $\mathrm{cm}$ depth in the locations of wells 1C, 1E, 2A, 2B, 2D, and $2 \mathrm{E}$, where significant correlation to surface stream diel temperature patterns was found, the exact cut-off point between the $\mathrm{HZ}$ and groundwater environments is difficult to pinpoint quantitatively without a thermal groundwater signature for the study location.

It is also possible that the maximum logger installation depth managed for this study was not deep enough to penetrate beyond the HZ. Even at $140 \mathrm{~cm}$ depth, seasonal temperature trends vary more than by the expected $\pm 3^{\circ} \mathrm{C}$ [10] range from the annual mean air temperature of $11.2^{\circ} \mathrm{C}$. A likely alternative explanation to lacking penetration depth is the impact of conduction on temperatures at depth [22]. While the presence of advecting surface water defines the extent of the $\mathrm{HZ}$, the presence of conduction may alter temperatures beyond the extent of the HZ, effectively masking the true groundwater thermal signature. Seasonal cross-correlation results between surface water and $140 \mathrm{~cm}$ depth at both sites (Figure 6) suggest at least $20 \%$ of the variability witnessed can still be explained by surface water variability. This may be coincidence, based on the large number of observations used in the correlation, as well as the small degree of change in the temperatures and the fact that groundwater also has a seasonal signal. However, if not coincidence, it seems possible that conduction could transmit $20 \%$ of the surface thermal signature to a depth of $140 \mathrm{~cm}$ below the streambed [22], especially considering that the seasonal trends are transmitted into the upper $30 \mathrm{~cm}$ by advection, leaving approximately $110 \mathrm{~cm}$ distance to be spanned by conduction.

\section{Conclusions}

Stream-groundwater interaction and HZ sediment physical and thermal properties are the major determining factors for temperature patterns within the HZ, simultaneously defining HZ flow paths of surface and groundwater, and the effectiveness of temperature transmission into the subsurface. Consequently, differences in one or all of these properties must exist between Sites 1 and 2 to explain the differences in temperature behavior, for al- 
though both site comparisons (Figures 7 and 8) show little difference between thermal gradients, local differences were observed in all other statistical results.

Overall, distinct differences were identified in the thermal profiles of Sites 1 and 2. Site 1 appears as a downwelling zone with surface water penetrating deepest into the $\mathrm{HZ}$ at the location of wells $1 \mathrm{C}$ and $1 \mathrm{E}$. Site 2 was characterized as a gaining reach, where the balancing between down-welling surface water and upwelling groundwater temperatures resulted in a more homogenized thermal environment. Additionally, a dampening of diel surface stream temperature ranges was noticed in upper $\mathrm{HZ}$ temperatures at Site 2. This dampening was attributed to a variety of possible causes, including a significant discharging groundwater component, which would produce a dampening effect on diel temperatures as previously outlined. This explanation is in line with Site 2 being recognized as a gaining reach. Additionally, the possibility of an increased percentage of finer sediments at the site was considered, resulting in slightly retarded inter-gravel flows causing dampening associated with the longer thermal transmission times.

A correlation between increased sediment homogeneity and more homogeneous thermal profiles was noted, though the lack of multiple sites makes definitive interpretation difficult. However, it has been established in the literature that larger sediment particles as well as possible low permeability zones can disrupt HZ flow paths and thermal regimes by altering the flowpaths[23,26].

The transmission of diel signals is limited by the efficiency of advection and diel thermal transfer requires higher transmission speeds than seasonal temperature signals. Supporting this, the deepest penetration depth of diel temperature patterns was $60 \mathrm{~cm}$ in well 1E, while seasonal surface temperature patterns were detected universally to a depth of $140 \mathrm{~cm}$.

Thermal differences in lateral and longitudinal profiles were detected, and were attributed to variations in factors affecting thermal transport, such as the presence of preferential flow paths. The longitudinal profile exhibited a greater tendency for progressive transmission of thermal signals in the downstream direction, though a thermal transmission against the direction of stream flow was detected at Site 1.

Finally, only qualitative delineation of the $\mathrm{HZ}$ was possible in this study.The main limitation was the lack of a specific thermal groundwater signature for the study area. The persistence of surface seasonal temperature trends beyond the extent of surface diel temperature is likely due to the influence of conduction on temperatures below the reach of advection [33,34].

Both sediment particle size and degree of sorting impact thermal profiles. Site 1 (poorly sorted gravels) showed a high degree of thermal heterogeneity through preferential flow paths (local downwelling zone). Site 2 (moderately sorted sands) showed a vertically and laterally homogenized thermal environment with no defined preferential flow paths. Meander flow-through discharge can have a significant impact on streambed temperatures. The transmission of diel signals is limited by the efficiency of advection, requiring higher transmission speeds than seasonal temperature signals. The deepest penetration depth of diel temperature patterns was $60 \mathrm{~cm}$ in well $1 \mathrm{E}$, where a local downwelling zone exists. Surface water temperatures influence the thermal regime not only of the hyporheic ecotone, but also of the shallow groundwater environment. Seasonal surface temperature patterns were detected universally to a depth of $140 \mathrm{~cm}$.

\section{Acknowledgements}

The authors would like to extend a sincere thank to the following organizations: The Bloomington Normal Wastewater Reclamation District for access to the study site. The Geological Society of America (student research grant-Beach), Grant-In-Aid of Research from Sigma Xi (student research grant-Beach), and the PADI Foundation, for funding of this study.

\section{REFERENCES}

[1] H. B. N. Hynes, "Ecology of Running Waters," Liverpool University Press, Liverpool, 1970.

[2] G. C. Poole and C. H. Berman, "An Ecological Perspective on In-Stream Temperature: Natural Heat Dynamics and Mechanisms of Human-CausedThermal Degradation," Environmental Management, Vol. 27, No. 6, 2001, pp. 787-802. doi:10.1007/s002670010188

[3] J. V. Ward, "THERMAL Characteristics of Running Waters," Hydrobiologia, Vol. 125, No. 1, 1985, pp. 31-46. doi:10.1007/BF00045924

[4] D. A. Stonestrom and J. Constantz, "Heat as a Tool for Studying the Movement of Ground Water Near Streams," US Geological Survey, Denver, 2003.

[5] B. Conant, "Delineating and Quantifying Ground Water Discharge Zones Using Streambed Temperatures," Ground Water, Vol. 42, No. 2, 2004, pp. 243-257. doi:10.1111/j.1745-6584.2004.tb02671.x

[6] F. Malard, A. Mangin, U. Uehlinger and J. V. Ward, "Thermal Heterogeneity in the Hyporheic Zone of a Glacial Floodplain," Canadian Journal of Fisheries and Aquatic Sciences, Vol. 58, No. 7, 2001, pp. 1319-1335. doi:10.1139/f01-079

[7] M. Hondzo and H. G. Stefan, "Riverbed Heat Conduction Prediction," Water Resources Research, Vol. 30, No. 5, 1994, pp. 1503-1513. doi:10.1029/93WR03508

[8] S. E. Silliman, J. Ramirez and R. L. McCabe, "Quantifing Downflow through Creek Sediments Using Temperature Time Series: One-Dimensional Solution Incorporating Measured Surface Temperature," Journal of Hydrology, Vol. 167, No. 1-4, 1995, pp. 99-119. 
doi:10.1016/0022-1694(94)02613-G

[9] M. Hayashi and D. O. Rosenberry, "Effects of Ground Water Exchange on the Hydrology and Ecology of Surface Water," Ground Water, Vol. 40, No. 3, 2002, pp. 309-316. doi:10.1111/j.1745-6584.2002.tb02659.x

[10] D. Deming, "Introduction to Hydrogeology," McGraw Hill, Boston, 2002.

[11] M. P. Anderson, "Heat as a Ground Water Tracer," Ground Water, Vol. 43, No. 6, 2005, pp. 951-968. doi:10.1111/j.1745-6584.2005.00052.x

[12] E. W. Peterson and T. B. Sickbert, "Stream Water Bypass through a Meander Neck, Laterally Extending the Hyporheic Zone," Hydrogeology Journal, Vol. 14, No. 8, 2006, pp. 1443-1451. doi:10.1007/s10040-006-0050-3

[13] C. Schmidt, M. Bayer-Raich and M. Schirmer, "Characterization of Spatial Heterogeneity of Groundwater-Stream Water Interactions Using Multiple Depth Streambed Temperature Measurements at the Reach Scale," Hydrology and Earth System Sciences Earth System Sciences Discussions, Vol. 3, 2006, pp. 1419-1446. doi:10.5194/hessd-3-1419-2006

[14] A. S. Arrigoni, et al., "Buffered, Lagged, or Cooled? Disentangling Hyporheic Influences on Temperature Cycles in Stream Channels," Water Resources Research, Vol. 44, No. 9, 2008, Article ID: W09418. doi:10.1029/2007WR006480

[15] T. J. Dogwiler and C. M. Wicks, "Thermal Variations in the Hyporheic Zone of a Karst Stream," Speleogenesis and Evolution of Karst Aquifers, Vol. 3, No. 1, 2005, pp. 1-11.

[16] D. S. White, C. Elzinga, H. and S. P. Hendricks, "Temperature Patterns within the Hyporheic Zone of a Northern Michigan River," Journal of North American Benthological Society, Vol. 6, No. 2, 1987, pp. 85-91. doi: $10.2307 / 1467218$

[17] C. E. Hatch, A. T. Fisher, J. S. Revenaugh, J. Constantz and C. Ruehl, "Quantifying Surface Water-Groundwater Interactions Using Time Series Analysis of Streambed Thermal Records: Method Development," Water Resources Research, Vol. 42, No. 10, 2006, Article ID: W10410.

[18] C. Schmidt, B. Conant Jr., M. Bayer-Raich and M. Schirmer, "Evaluation and Field-Scale Application of a Simple Analytical Method to Quantify Groundwater Discharge Using Mapped Streambed Temperatures," Journal of Hydrology, 2007.

[19] B. G. Fraser and D. D. Williams, "Seasonal Boundary Dynamics of a Groundwater/Surface-Water Ecotone," Ecology, Vol. 79, No. 6, 1998, pp. 2019-2031.

[20] A. Mangin, "For a Better Knowledge of Hydrological Systems from Correlogram and Variance Spectral Density," Journal of Hydrology, Vol. 67, No. 1-4, 1984, pp. 25-43. doi:10.1016/0022-1694(84)90230-0

[21] E. C. Evans, M. T. Greenwood and G. E. Petts, "Thermal Profiles within River Beds," Hydrological Processes, Vol. 9, No. 1, 1995, pp. 19-25. doi:10.1002/hyp.3360090103
[22] E. T. Hester, M. W. Doyle and G. C. Poole, "The Influence of In-Stream Structures on Summer Water Temperatures via Induced Hyporheic Exchange," Limnology and Oceanography, Vol. 54, No. 1, 2009, pp. 355-367. doi:10.4319/10.2009.54.1.0355

[23] W. G. Vaux, "Intergravel Flow and Interchange of Water in a Streambed," Fishery Bulletin, Vol. 66, No. 3, 1968, pp. 479-489.

[24] A. C. Cooper, "The Effect of Transported Stream Sediments on the Survival of Sockeye and Pink Salmon Eggs and Alevins," International Pacific Salmon Fishery Commission Bulletin, Vol. 18, 1965, p. 75.

[25] N. H. Ringler and J. D. Hall, "Effects of Logging on Temperature, and Dissolved Oxygen in Spawning Beds," Transactions of the American Fisheries Society, Vol. 104, No. 1, 1975, pp. 111-121. doi:10.1577/1548-8659(1975)104<111:EOLOWT>2.0.C $\underline{\mathrm{O} ; 2}$

[26] M. W. Becker, T. Georgianb, H. Ambrosea, J. Siniscalchia and K. Fredricka, "Estimating Flow and Flux of Ground Water Discharge Using Water Temperature and Velocity," Journal of Hydrology, Vol. 296, No. 1-4, 2004, pp. 221-233. doi:10.1016/j.jhydrol.2004.03.025

[27] "SPSS for Windows Rel. 16.0.1.," SPSS Inc., Chicago, 2007.

[28] G. M. Jenkins and D. G. Watts, "Spectral Analysis and Its Applications," Holden-Day, San Francisco, 1968.

[29] M. Brunke and T. Gonser, "The Ecological Significance of Exchange Processes between Rivers and Groundwater (Special Review)," Freshwater Biology, Vol. 37, No. 1, 1997, pp. 1-33. doi:10.1046/j.1365-2427.1997.00143.x

[30] M. S. Buyck, "Tracking Nitrate Loss and Modeling Flow through the Hyporheic Zone of a Low Gradient Stream through the Use of Conservative Tracers," Illinois State University, Normal, 2005.

[31] S. van der Hoven, N. Fromm and E. Peterson, "Quantifing Nitrogen Cycling Beneath a Meander of a Low Gradient, N-Impacted, Agricultural Stream Using Tracers and Numerical Modelling," Hydrological Processes, Vol. 22, No. 8, 2008, pp. 1206-1215.

[32] B. G. Shepherd, G. F. Hartman and W. J. Wilson, "Relationships between Stream and Intragravel Temperatures in Coastal Drainages and Some Implications for Fisheries Workers," Canadian Journal of Fisheries and Aquatic Sciences, Vol. 43, No. 9, 1986, pp. 1818-1822. doi:10.1139/f86-226

[33] E. Hoehn and O. A. Cirpka, “Assessing Hyporheic Zone Dynamics in Two Alluvial Flood Plains of the Southern Alps Using Water Temperature and Tracers," Hydrology and Earth System Sciences Discussions, Vol. 3, No. 2, 2006, pp. 335-364. doi:10.5194/hessd-3-335-2006

[34] W. W. Lapham, "Use of Temperature Profiles Beneath Streams to Determine Rates of Vertical Ground-Water Flow and Vertical Hydraulic Conductivity," United States Geological Survey, Reston, 1989, p. 35. 